ave been carried out in Wiltshire as an eastern zontinuation of the Somerset Coalfield, or there may be an independent coalfield, in the Cotswold country of Gloucestershire and in southern Worcester. shire, and in certain areas in Oxfordshire-between Oxford and Reading. Work in eastern Essex was also contemplated. In all the above areas there is a possibility of coal being found. Other areas are under consideration, including extensions of present known coalfields.

\title{
UNITED NATIONS CONFERENCE ON THE CONSERVATION AND UTILIZATION OF RESOURCES
}

AEPORT by the Secretary-General of the United Nations, presented as a result of the decision of the Economic and Social Council on March 28, 1947, to call a Scientific Conference on the Conservation and Utilization of Resources, for the purpose of exchanging information on techniques in this field, their economic costs and benefits and their interrelations, recommends that the Conference should be held in the United States during May 16-June 3, 1949. A note on the financial implications is being prepared on the assumption that it will be held at Lake Success; but possibilities of another location are being explored. Four classes of participants in the Conference are contemplated: representatives from Government services, members of non-Government services and individuals selected by member Governments; individual specialists selected with the advice of the Preparatory Committee to prepare papers or to lead discussion, invited by the Secretary-General, in consultation with the Governments concerned; representatives of the United Nations and its specialized agencies; and representatives of interested intermational organisations and learned societies, and distinguished members of the professions, to be admitted at the discretion of the Secretary-General.

The primary concern of the Conference is with the practical applications of science to public administration and human needs, rather than with minute refinements in research and scientific methodology, and the Conference should serve a uniquely important function by bringing together experts from many related fields. About half the time of the Conference will he given to primary sessions on subjects of general interest such as resource requirements for industrialization, the contribution of improved agriculture to living standards, the planning of multiple use development of regional resources, education in conservation, and the sources and methods for mobilization of capital and man-power for resource development. Technical sessions in the remaining half of the programme will give experts concurrent opportunity of exchanging information on minerals, fuels, power, water, soils, crops, livestock, forests, fish and wild-life, and though primarily devoted to the discussion of methods for the development of natural resources, will reflect the importance in such developments of techniques relating to standards of health and living. Particular attention will be devoted to the special problems of the under-developed countries.

These technical sessions may be expected to stimulate the economic development of such countries by defining the technical knowledge gained in the last decade in determining the resource requirements for various types of industrialization, by exploring the technical problems involved in raising the standard of living by increased agricultural production, by considering the institution of new techniques and by the modification of existing curricula to facilitate the provision of trained personnel in such countries and by directing the attention of the scientific men and technicians of the world to the research and design problems of these areas. A draft programme is being prepared for circulation to all members of the United Nations for comment, and the Secretary-General also proposes to establish a standing Preparatory Committee as well as to convene in certain regions informal meetings of experts. The Economic and Social Council is also being requested to establish a small temporary Consultative Committee representing about six member Governments.

\section{FORTHCOMING EVENTS}

(Meetings marked with an asterisk * are open to the public)

\section{Tuesday, April 20}

ROXal SOcIETY OF ARTS, DOMINIONS AND COLONIES SECTION (at John Adım Street, Adelphi, London, W.C.2), at 2.30 p.m.-Mr. A. J. Wakefleld : "The New East African Ground Nuts Scheme".

SOCIETY OF CHEMICAL INDUSTRY, AGRICULTURE GRodP (in the Chemistry Department, Royal College of Science, Imperial Institute Road, London, S.W.7), at 2.30 p.m.-Dr. W. G. C. Forsyth : "Carbohydrate Metabolism in Soil"."

Royal ANTHRopological Institute (at 21 Bedford Square, London, W.C.1) at 5 p.m.-Colonel D. H. Gordon: "The Prehistoric don, W.C.1), at 5 p.m.-Colonel D. H. Gordon: "The

Institute of Physios, Electronics GrodP (at 47 Belgrave Square, London, S.W.1), at 5.30 p.m.-Dr. C. J. Milner : "Long-Wave InfraRed Detectors"'

Institution of Civil Engineres (at Great George Street, London, INSTITUTION OF Crvil ENGINkRRS (at Great George Street, London, and Remedial Measures Taken",

MANCHESTER Grographican Soctety (in the Geographical Hall, St. Mary's Parsonage, Manchester), at 6.30 p.m.-Mr. L. Brooks : "Geography in Education and Citizenship".

OIL AND COLOUR ChEMISTS' Association (at the Royal Society of Tropical Medicine and Hygiene, Manson House, 26 Portland Place, London, W.1), at 7 p.m.-Mr. K. McTaggart : "Esters of Titanium".

Royal Photographic Society, Scientific and Technical Group (at 16 Prince's Gate, London, S.W.7), at 7 p.m.-Symposium on "Modern Techniques in Stereoscopy".

Sheffield Metallorgical Association (at 198 West Street, Sheffield), at 7 p.m.-Mr. F. Turner: "Some Applications of the Supersonic Frequency Detector in Steelworks Inspection".

SOCIETY OF DYERS AND CoLOURISTS, SCOTMISH SECTION (at St. Enoch Hotel, Glasgow), at 7 p.m. -Mr. G. H. Lister: "An Investigation into the Practical Ȧspects of the Absorption of Acid and Chrome tion into the Practic

BRITish Poush Societr (at the Polish Institute, 81 Portland Place, London, W.1), at 8 p.m.--Prof. S. Loria: "The Organisation of Scientific and Cultural Life in Wroclaw".*

\section{Wednesday, April 21}

TExtiue InstrTuTe (in the Council Chamber, Town Hall, Macclesfield), at 12 noon.-Annual General Meeting; at 2.30 p.m.-Mr. Allan, Walton: "Art in relation to the Textile Industry" (Mather Lecture).

INSTITrTE of Frar (at the Institution of Mechanical Engineers, Storey's Gate, London, S.W.1) at 2.30 p.m.-Dr. D. T. A. Townend : "Recent Developments in Combustion"."

ROYAL SOCIETY of ARTs (at John Adam Street, Adelphi, London W.C.2), at 2.30 p.m.--Sir Robert Robinson, P.R.S.: "The Structura Relationships of some Plant Products" (Trueman Wood Lecture).

ROYAL INSTITUTE OF CHEMTSTRY, LONDON AND SOUTH-EASTRRN CoUNTIES SECTION (at the London School of Hygiene and Tropica Medicine, Keppel Street, London, W.C.1), at 4 p.m.-Symposium on "Laboratory Layout and Construction".

Grologicar SOCIETY of LONDON (at Burlington House, Piccadilly, London, W.1), at 5 p.m.- Scientific Papers.

Royal METEOROLOGical SOCIBTy (at 49 Cromwell Road, London, S.W.7), at 5 p.m.-Dr. H. G. Booker: "Some Problems of RadioMeteorology" (Symons Memorial Lecture).

ROYAI MroRoscopical SOCIETY (in the Hastings Hall, B.M.A. House, Tavistock Square, London, W.C.1), at 5.30 p.m.-Dr. E. S Horning: "Researches on Cosmic Radiations at the High Alpin Scientific Station, Jungfraujoch"; Dr. E. P. George: "Physical Properties of Cosmic Radiation". 